\title{
Dioxolanylium Ions Derived from Carbohydrates. VII. Rearrangements between Derivatives of Methyl $\alpha$-D-Manno-, Altro- and Iodopyranosides and Their Reaction with Nucleophiles
}

\author{
STEFFEN JACOBSEN and OLE MOLS
}

Department of Organic Chemistry, The Technical University of Denmark, DK-2800 Lyngby, Denmark

Reaction of derivatives of methyl 2,3-O-benzylidene$\alpha$-D-mannopyranoside or 3,4-O-benzylidene- $\alpha$ - $D$ altropyranoside with trityl fluoroborate gave the same equilibrium mixture of benzoxonium ions $(4 \rightleftarrows 5 \rightleftarrows 6$ ) of the manno, altro and ido configuration. Through introduction of stabilizing or destabilizing substitutents into the benzoxonium ions, it was possible to shift the equilibrium enough to allow observation and description of one of the benzoxonium ions at a time. Treatment of the equilibrating benzoxonium ions with bromide ion gave products resulting from trans-opening of all three benzoxonium ions.

The preceding paper ${ }^{1}$ described the formation of benzoxonium ions derived from galacto- and gulopyranosides and the reactions and rearrangements of these ions. The present paper describes the formation of the corresponding pair of benzoxonium ions derived from manno- and altropyranosides, their rearrangement and reaction with nucleophiles.

Treatment of methyl 4,6-di-O-benzoyl-2,3-O- benzylidene- $\alpha$-D-mannopyranoside (1a) with trityl fluoroborate in acetonitrile gave a mixture of three benzoxonium ions in approximately equal amounts as apparent from a ${ }^{13} \mathrm{C}$ NMR spectrum (Table 1). Hydrolysis of the reaction mixture followed by debenzoylation gave a mixture of three glycosides, methyl $\alpha$-D-manno, $\alpha$-D-altro- and $\alpha$-D-idopyranoside in a ratio of $48: 28: 24$, indicating that the benzoxonium ions formed were $4 a, 5 a$ and $6 a$. The mannobenzoxonium ion $4 a$ is the primary reaction product resulting from hydride abstraction from the benzylidene-mannoside $1 a$, while the altro- and idobenzoxonium ions $5 a$ and $6 a$ are rearrangement products formed as a result of neighbouring group participation, first by the acyloxy group at $\mathrm{C}-4$ and then by the group at $\mathrm{C}-6$. When methyl 2,6-di-O-benzoyl-3,4-Obenzylidene- $\alpha$-D-altropyranoside $(2 a)$ was treated with trityl fluoroborate the primary product was the altrobenzoxonium ion $(5 a)$, subsequently rearranging to the manno- and idobenzoxonium ions $4 a$ and $6 a$. In this case hydrolysis followed by

Table $1 .{ }^{13} \mathrm{C}$ Chemical shifts ( $\delta$-values) of benzoxonium ions in acetonitrile- $d_{3}$ solution.

\begin{tabular}{llllllll}
\hline Compound & C1 & C2 & C3 & C4 & C5 & C6 & C+ \\
\hline $4 a$ & 95.0 & 85.1 & 87.5 & $66.3^{a}$ & $65.0^{a}$ & 62.6 & \\
$4 b$ & 95.0 & 84.8 & 87.1 & $67.0^{a}$ & $64.5^{a}$ & 63.2 & \\
$5 a$ & 97.5 & $67.0^{a}$ & 81.7 & 85.1 & $65.6^{a}$ & 63.0 & \\
$5 c$ & 97.4 & $67.1^{a}$ & 80.3 & 83.7 & $65.5^{a}$ & 63.0 & 179.5 \\
$6 a$ & 98.7 & 64.9 & 64.6 & 75.7 & 55.5 & 75.7 & \\
$6 d$ & 98.5 & 65.0 & 64.5 & 74.7 & 55.5 & 74.4 & 174.7 \\
\hline
\end{tabular}

assignment may be reversed. 

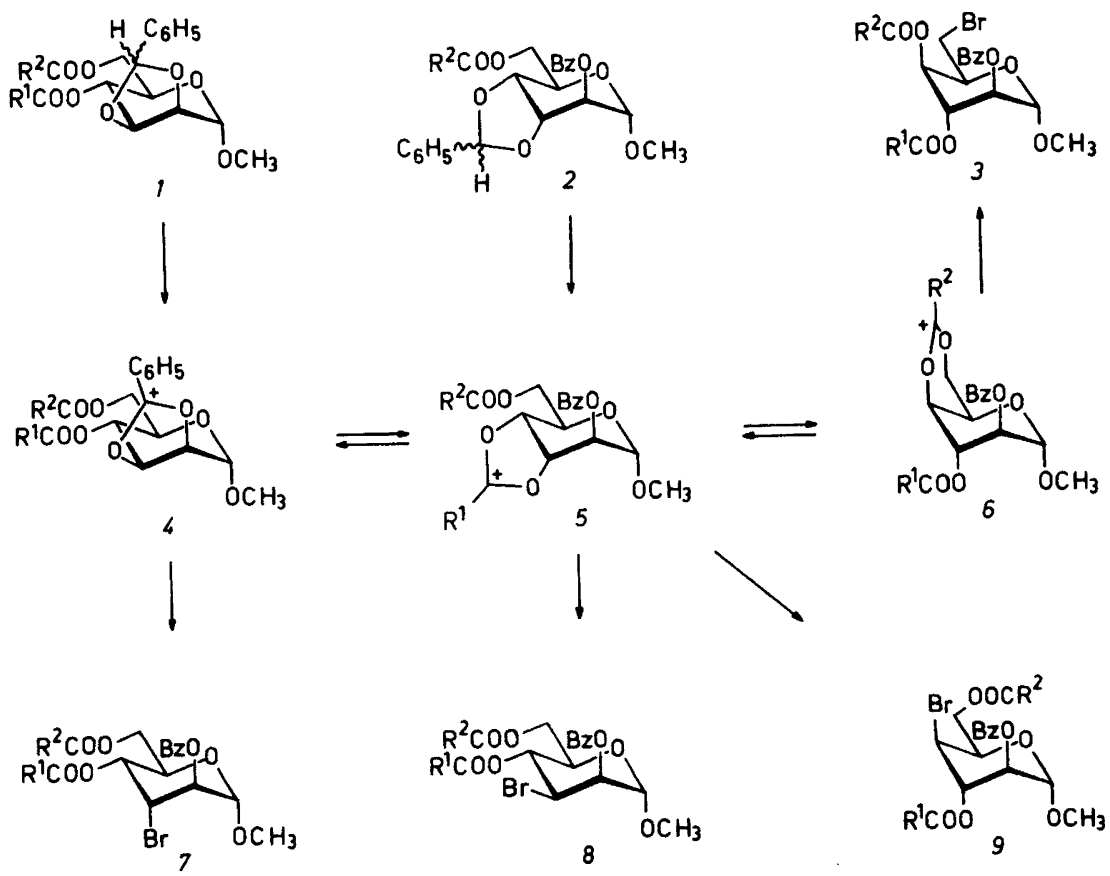

a: $R^{1}=R^{2}=C_{6} H_{5}$
b: $R^{1}=R^{2}=\rho-N_{2}-C_{6} H_{5}$

debenzoylation gave the methyl manno-, altro- and idosides in a ratio of $34: 43: 23$. The discrepancy between the product distributions found when starting from the benzylidene-mannoside and altroside is due to a small amount of hydrolysis of the benzylidene compounds under the prevailing acidic conditions, resulting in products, which upon hydrolysis and debenzoylation show up as methyl glycosides. Therefore, when starting from a mannose derivative, the manno ion content is overestimated and similarly when starting from the altrose derivative altro ion content is overestimated, while in the first case the altroside-idoside ratio and in the latter case the mannoside-idoside ratio accurately reflects the relative amounts of the corresponding benzoxonium ions in the equilibrium. In this manner the equilibrium mixture between the manno-, altroand idobenzoxonium ions can be calculated to contain $43 \%$ of $4 a, 32 \%$ of $5 a$ and $27 \%$ of $6 a$. This result resembles the results obtained by Paulsen ${ }^{2}$ when observing the gluco-, manno-, altro- and idobenzoxonium ion equilibrium established when 2,3,4,5-tetra- $O$-benzoyl- $\alpha$-D-glucopyranosyl chloride is treated with antimony pentachloride in acetonitrile. In this case also, the equilibrating manno, altro and ido ions were found to be of comparable stability (ratio 14:3:5) although the manno ion played a somewhat more prominent role in this system.

In order to allow a more direct observation of the benzoxonium ions mentioned above a number of derivatives were prepared, in which $p$-methoxy and $p$-nitro-substituents were attached to the benzoyl groups in order to stabilize or destabilize ${ }^{3}$ some of the equilibrating ions to the extent that the ions could be observed and studied one at a time. Oxidation of methyl 2,3-O-benzylidene-4,6-di-O-pnitrobenzoyl- $\alpha$-D-mannopyranoside $(1 b)$ with trityl fluoroborate gave the mannobenzoxonium ion $4 b$, methyl 6-O-benzoyl-2,3-O-benzylidene-4-O-pmethoxybenzoyl- $\alpha$-D-mannopyranoside (1d) gave the altrobenzoxonium ion $5 c$ and methyl 4-O- 
Table 2. ${ }^{1} \mathrm{H}$ NMR spectra of benzoxonium ions in acetonitrile- $d_{3}$ solution $(270 \mathrm{MHz})$.

\begin{tabular}{|c|c|c|c|c|c|c|c|c|c|c|c|c|c|c|}
\hline \multirow[t]{2}{*}{ Compound } & \multicolumn{8}{|c|}{ Chemical shifts ( $\delta$ values) } & \multicolumn{6}{|c|}{ Coupling constants $(\mathrm{Hz})$} \\
\hline & H1 & $\mathrm{H} 2$ & H3 & H4 & H5 & H6 & $\mathbf{H} \mathbf{6}^{\prime}$ & $\mathrm{CH}_{3}$ & $J_{12}$ & $J_{23}$ & $J_{34}$ & $J_{45}$ & $J_{56}$ & $J_{56}$ \\
\hline $\begin{array}{c}4 a \\
4 b \\
5 a\end{array}$ & $\begin{array}{l}5.56 \\
5.59 \\
5.11\end{array}$ & $\begin{array}{l}5.74 \\
5.84 \\
5.78\end{array}$ & $\begin{array}{l}6.43 \\
6.48 \\
6.2-\end{array}$ & $\begin{array}{l}5.77 \\
-6.3\end{array}$ & 4.56 & 4.68 & 4.67 & $\begin{array}{l}3.55 \\
3.59 \\
3.37\end{array}$ & $\begin{array}{l}0 \\
0 \\
4.0\end{array}$ & $\begin{array}{l}9.0 \\
9.2\end{array}$ & $\begin{array}{l}5.5 \\
5.5\end{array}$ & 9.4 & $\simeq 4$ & $\simeq 4$ \\
\hline $5 c$ & 5.08 & 5.68 & $6.05-$ & -6.1 & 4.7 & - & -4.8 & $\begin{array}{l}3.38 \\
4.01\end{array}$ & 3.8 & $3-4$ & & & & \\
\hline $6 a$ & 5.16 & 5.22 & 5.57 & 5.92 & 5.05 & -5.4 & 4 & 3.58 & all & $J<3$ & $\mathrm{~Hz}$ & & & \\
\hline $6 d$ & 5.08 & 5.17 & 5.45 & 5.87 & 5.03 & -5.2 & 24 & $\begin{array}{l}3.58 \\
3.94\end{array}$ & 1.5 & 1.0 & 2.5 & & & $J_{13} \simeq 1, J_{24} \simeq 2$ \\
\hline
\end{tabular}

benzoyl-2,3-O-benzylidene-6- $O$ - $p$-methoxybenzoyl$\alpha$-D-mannopyranoside (1d) gave the idobenzoxonium ion $6 d$, all having well-resolved ${ }^{1} \mathrm{H}$ NMR spectra (Table 2) allowing assignment of the ${ }^{13} \mathrm{C}$ NMR spectra through selective decoupling experiments (Table 1).

Reaction of the equilibrating manno-, altro- and idobenzoxonium ions $4 a, 5 a$ and $6 a$ with bromide ion gave a mixture of four bromo-deoxy compounds in approximately equal amounts, methyl 2,4,6tri- $O$-benzoyl-3-bromo-3-deoxy- $\alpha$-D-altropyranoside (7a, $23 \%$ ), methyl 2,4,6-tri-O-benzoyl-3-bromo3-deoxy- $\alpha$-D-mannopyranoside $(8 a, 22 \%)$, methyl 2,3,6-tri-O-benzoyl-4-bromo-4-deoxy- $\alpha$-D-idopyranoside $(9 a, 23 \%)$ and methyl 2,3,4-tri-O-benzoyl6-bromo-6-deoxy- $\alpha$-D-idopyranoside $(3 a, 32 \%)$. The 6-bromo-deoxy-idose derivative could be crystallized from the mixture, while the remaining three bromodeoxy compounds proved difficult to separate chromatographically. Since the outcome of the reaction of a pair of equilibrating manno-, and altrobenzoxonium ions with bromide ion can be deduced from the studies of Monneret ${ }^{4}$ and Thiem ${ }^{5}$ on the reaction between 2,3:4,6-di-O-benzylidene- $\alpha$ D-mannopyranoside and $\mathrm{N}$-bromosuccinimide, the separation of these compounds was carried out only to a point allowing spectroscopic identification of the products. The amount of the 6-bromo-6deoxy-idose derivative resulting from attack on the ido ion $6 a$ corresponds roughly to the amount of ido ion present in the equilibrium. This is a somewhat surprising result, since, the axial attack on both the manno and altro ions being unfavorable due to 1,3-diaxial interactions, ${ }^{6}$ one would expect preferential attack on the easily accessible C-6 in the ido ion. A possible explanation for this behavior may be that the equilibration between a dioxanylium ion (6a) and a dioxolanylium ion $(5 a)$ is much slower than the reaction with bromide ion, in contrast to the case of two equilibrating dioxolanylium ions, where the reaction with bromide ion is slower than the equilibration. ${ }^{3}$ This explanation is supported by the observation by Paulsen ${ }^{2}$ that the crystalline 4,6-acetoxonium ion of idopyranose triacetate reacts with lithium bromide without rearrangement to altro-, manno- and glucoacetoxonium ions to give 1,2,3,4-tetra- $O$-acetyl-6-bromo-6deoxy- $\alpha$-D-idopyranose exlusively when the reaction is carried out "rapidly" 2 at $-20^{\circ} \mathrm{C}$.

A summary of the results obtained here and the results obtained in the previous papers in this series, ${ }^{1,3,11,14-16}$ allows the following conclusions to be drawn with regard to the behavior of carbohydrate acyloxonium ions in acetonitrile solution:

1. A vicinal trans acyloxy group allows rearrangement to a new acyloxonium ion.

2. A 1,3-neighbouring group rearrangement takes place only from an exocyclic trans acyloxy-methyl group and not with acyloxy groups located on the furanose or pyranose ring.

3. Reaction with water proceeds faster than rearrangement and gives cis 1,2-hydroxy esters, which in the case of pyranosides have the acyloxy group in an axial and the hydroxy group in an equatorial position.

4. Reaction with bromide ion gives trans acyloxy bromides. In the case of pyranose derivatives the preferred opening is trans diaxial, unless either a 1,3-diaxial substituent is present or the attack site is $\mathrm{C}-2$, in which case the opening with bromide ion may change partially to trans diequatorial or rearrangement of the acyloxonium ion may take place with subsequent attack on the rearranged acyloxonium ion. Rearrangement between 1,2- 
acyloxonium ions is faster than the reaction with bromide ion, whereas in the much rarer case of rearrangement between a 1,2- and a 1,3-acyloxonium ion this need not be so.

The benzylidene mannosides were prepared from the easily available methyl 2,3-O-isopropylidene- $\alpha$-D-mannopyranoside, ${ }^{7}$ which was selectively acylated at 0-6 and subsequently at $0-4$ with the appropriate acyl halides, followed by hydrolysis and transacetalization with benzaldehyde dimethylacetal. ${ }^{8}$ The benzylidene-altroside was prepared from methyl 2,3-anhydro- $\alpha$-D-mannopyranoside ${ }^{9}$ by benzoylation followed by rearrangement to the 3,4-altrobenzoxonium ion with boron trifluoride and subsequent reduction to the benzylidene compound with sodium borohydride in analogy to Buchanan's procedure. ${ }^{10}$

\section{EXPERIMENTAL}

For general experimental details see the preceding paper. $^{1}$

Methyl 2,6-di-O-benzoyl-3,4-O-benzylidene- $\alpha-\mathrm{D}-$ altropyranoside (2a). Methyl 2,3-anhydro- $\alpha-\mathrm{D}-$ mannopyranoside ${ }^{9}(1.60 \mathrm{~g})$ was benzoylated with benzoyl chloride $(3.0 \mathrm{ml})$ in pyridine $(25 \mathrm{ml})$. To the crude product in acetonitrile $(20 \mathrm{ml})$ at $0{ }^{\circ} \mathrm{C}$ was added $1.12 \mathrm{ml}$ of boron trifluoride etherate, the clear solution was stirred for $5 \mathrm{~min}$ at $0{ }^{\circ} \mathrm{C}, 0.52 \mathrm{~g}$ of finely powdered sodium borohydride was added and the solution was stirred for a further $20 \mathrm{~min}$ at $0{ }^{\circ} \mathrm{C}$. After addition of water the resulting solution was neutralized with acetic acid and the benzylidene compound extracted with chloroform, the organic phase washed with aqueous $\mathrm{NaHCO}_{3}$, dried and evaporated to dryness. The residue was benzoylated with benzoyl chloride $(1.5 \mathrm{ml})$ in pyridine $(25 \mathrm{ml})$ to give crude $2 a$ as an epimeric mixture with the exo-H isomer dominating (5:1). Equilibration of the epimeric mixture by reflux for $1 \mathrm{~h}$ with p-toluenesulfonic acid (100 mg) in chloroform $(50 \mathrm{ml})$ allowed crystallization of a product $(1.8 \mathrm{~g}$, $43 \%$ ) from ether with the endo-H isomer dominating (10:1), m.p. $120-135{ }^{\circ} \mathrm{C}$. Recrystallization from ethyl acetate and from ethanol raised the m.p. to $146-148{ }^{\circ} \mathrm{C}$, but both epimers could still be observed in the product (NMR). Anal. $\mathrm{C}_{28} \mathrm{H}_{26} \mathrm{O}_{8}: \mathrm{C}, \mathrm{H}$. ${ }^{1} \mathrm{H}$ NMR: $\delta 6.28$ and $5.91(\mathrm{ArCH}), 3.45$ and 3.42 $\left(\mathrm{OCH}_{3}\right)$.

Methyl 4,6-di-O-benzoyl-2,3-O-benzylidene- $\alpha$-Dmannopyranoside (1a). Methyl 2,3-O-isopropylidene- $\alpha$-D-mannopyranoside ${ }^{7}(2.63 \mathrm{~g})$ was benzoylated with benzoyl chloride in pyridine and the resulting crude dibenzoate hydrolyzed with $75 \%$ acetic acid $\left(1 \mathrm{~h}, 100^{\circ} \mathrm{C}\right)$. The resulting solution was evaporated to dryness and refluxed with benzaldehyde dimethylacetal $(2.5 \mathrm{ml})$ and $p$-toluenesulfonic acid $(0.1 \mathrm{~g})$ in DMF $(20 \mathrm{ml})$ under water aspirator vacuum for $1 \mathrm{~h}$. Evaporation to dryness, addition of aqueous $\mathrm{NaHCO}_{3}$ and extraction with chloroform gave the crude benzylidene compound $1 a$, which on preparative TLC (ethyl acetatepentane, $2: 3)$ gave $2.90 \mathrm{~g}(53 \%)$ of sirupy $1 a$ as an epimeric mixture with the exo-H isomer dominating (5:1). Anal. $\mathrm{C}_{28} \mathrm{H}_{26} \mathrm{O}_{8}: \mathrm{C}, \mathrm{H} .{ }^{1} \mathrm{H}$ NMR: $\delta 6.28$ and $5.95(\mathrm{ArCH}), 3.41\left(\mathrm{OCH}_{3}\right)$.

Methyl 2,3-O-benzylidene-4,6-O-p-nitrobenzoyl$\alpha$-D-mannopyranoside (1b). $p$-Nitrobenzoylation of methyl 2,3-O-isopropylidene- $\alpha$-D-mannopyrano$\operatorname{side}^{7}(2.34 \mathrm{~g})$ with $p$-nitrobenzoyl chloride $(4.0 \mathrm{~g})$ in pyridine $(20 \mathrm{ml})$ gave $3.15 \mathrm{~g}(59 \%)$ of methyl 2,3-O-isopropylidene-4,6-di- $O$ - $p$-nitrobenzoyl- $\alpha$-Dmannopyranoside (10), m.p. $152-153{ }^{\circ} \mathrm{C}$ (from acetone-ethanol), $[\alpha]_{\mathrm{D}^{23}}+64^{\circ} \quad$ (c 1.1), anal. $\mathrm{C}_{24} \mathrm{H}_{24} \mathrm{~N}_{2} \mathrm{O}_{12}: \mathrm{C}, \mathrm{H}, \mathrm{N}$. Treatment of $10(3.15 \mathrm{~g})$ with trifluoroacetic acid - water $(9: 1)$ at room temperature for $10 \mathrm{~min}$, followed by evaporation to dryness and acid catalyzed transacetalization with benzaldehyde dimethylacetal as described above gave $1 b, 2.50 \mathrm{~g}(73 \%)$ as a foam consisting of both epimeric benzylidene compounds. Anal. $\mathrm{C}_{28} \mathrm{H}_{24} \mathrm{~N}_{2} \mathrm{O}_{12}: \mathrm{C}, \mathrm{H}, \mathrm{N} .{ }^{1} \mathrm{H}$ NMR: $\delta 6.31$ and 5.98 $(\mathrm{ArCH}), 3.48$ and $3.46\left(\mathrm{OCH}_{3}\right)$.

Methyl 6-O-benzoyl-2,3-O-benzylidene-4-O-pmethoxybenzoyl- $\alpha$-D-mannopyranoside (1c). To a solution of $20.0 \mathrm{~g}$ of methyl 2,3-O-isopropylidene$\alpha$-D-mannopyranoside ${ }^{7}$ in $50 \mathrm{ml}$ pyridine at $-30^{\circ} \mathrm{C}$ was added $10.4 \mathrm{ml}$ of benzoyl chloride in $100 \mathrm{ml}$ methylene chloride over $30 \mathrm{~min}$, the solution was allowed to come to room temperature overnight and then heated to $40{ }^{\circ} \mathrm{C}$ for $1 \mathrm{~h}$. To the resulting solution was added $17.4 \mathrm{ml}$ of $p$-methoxybenzoyl chloride and work-up in the usual manner gave a crude product, which was hydrolyzed with $75 \%$ acetic acid at $100{ }^{\circ} \mathrm{C}$ for $1 \mathrm{~h}$. Evaporation to dryness and crystallization from ether gave $27.8 \mathrm{~g}(75 \%)$ of 6-O-benzoyl-4-O-p-methoxybenzoyl- $\alpha$-D-mannopyranoside (11), m.p. $105-109^{\circ} \mathrm{C}$. Recrystallization from ethyl acetate - pentane gave m.p. $112-113^{\circ} \mathrm{C}$, $[\alpha]_{D}^{25}+110^{\circ}(c 1.1)$, anal. $\mathrm{C}_{22} \mathrm{H}_{24} \mathrm{O}_{9}: \mathrm{C}, \mathrm{H}$. Transacetalization of $11(2.60 \mathrm{~g})$ with benzaldehyde dimethylacetal as described above gave the sirupy $1 c(1.85 \mathrm{~g}, 59 \%)$ as an epimeric mixture with the exo-H isomer dominating (3:1). Anal. $\mathrm{C}_{29} \mathrm{H}_{28} \mathrm{O}_{9}: \mathrm{C}, \mathrm{H} .{ }^{1} \mathrm{H}$ NMR: $\delta 6.22$ and 5.85(ArCH), 3.69 and $3.34\left(\mathrm{OCH}_{3}\right)$.

Methyl 4-O-benzoyl-2,3-O-benzylidene-6-O-pmethoxybenzoyl- $\alpha$-D-mannopyranoside (1d). Selective anisoylation of methyl 2,3-O-isopropylidene- $\alpha$-D-mannopyranoside ${ }^{7}$ followed by benzoylation as described for $1 c$ gave a $62 \%$ yield of methyl 4-O-benzoyl-2,3-O-isopropylidene-6-O-pmethoxybenzoyl- $\alpha$-D-mannopyranoside (12), m.p. 
$105-108^{\circ} \mathrm{C}$. Recrystallization from ethanol gave m.p. $112-113^{\circ} \mathrm{C},[\alpha]_{\mathrm{D}}^{25}+37^{\circ}$ (c) 0.9 , anal. $\mathrm{C}_{25} \mathrm{H}_{28} \mathrm{O}_{9}: \mathrm{C}, \mathrm{H},{ }^{1} \mathrm{H} \mathrm{NMR}: \delta 3.89$ and $3.39\left(\mathrm{OCH}_{3}\right)$,

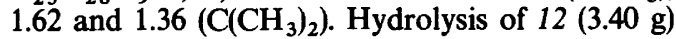
with $75 \%$ acetic acid $\left(1 \frac{1}{2} \mathrm{~h}, 100^{\circ} \mathrm{C}\right)$ and evaporation to dryness gave $2.84 \mathrm{~g}(91 \%)$ of methyl 4-O-benzoyl6-O-p-methoxybenzoyl- $\alpha$-D-mannopyranoside (13), m.p. $124-125^{\circ} \mathrm{C}$ (from ethanol). Recrystallization from ethyl acetate - pentane gave m.p. $126-127^{\circ} \mathrm{C}$, $[\alpha]_{\mathrm{D}}^{25}+100^{\circ}(c 0.9)$, anal. $\mathrm{C}_{22} \mathrm{H}_{24} \mathrm{O}_{9}: \mathrm{C}, \mathrm{H}$. Transacetalization of $13(2.00 \mathrm{~g})$ with benzaldehyde dimethylacetal as described above gave $1.70 \mathrm{~g}(71 \%)$ of $1 d$ as a sirupy mixture of epimers. Anal. $\mathrm{C}_{29} \mathrm{H}_{28} \mathrm{O}_{9}: \mathrm{C}, \mathrm{H} .{ }^{1} \mathrm{H} \mathrm{NMR}: \delta 6.31$ and $5.94(\mathrm{ArCH})$, $3.82\left(\mathrm{ArOCH}_{3}\right), 3.45$ and $3.43\left(\mathrm{OCH}_{3}\right)$.

Reaction between the equilibrating manno-, altroand indobenzoxonium ions and bromide ion. Methyl 4,6-di- $O$-benzoyl-2,3- $O$-benzylidene- $\alpha$-D-mannopyranoside $(1 a, 1.008 \mathrm{~g})$ was treated with trityl fluoroborate $(820 \mathrm{mg})$ in acetonitrile $(10 \mathrm{ml})$ overnight. Tetraethylammonium bromide $(1.25 \mathrm{~g})$ was added and the solution was stirred at room temperature for $3 \mathrm{~h}$. Addition of aqueous $\mathrm{NaHCO}_{3}$ and extraction with chloroform gave a crude reaction mixture which on preparative TLC (ethyl acetate pentane, 1:3) among other fractions gave one fraction $(650 \mathrm{mg})$ containing four bromo-deoxy compounds as seen from a ${ }^{13} \mathrm{C}$ NMR spectrum. Since ${ }^{1} \mathrm{H}$ NMR revealed a small content of starting material, this fraction was treated with $75 \%$ acetic acid for $1 \mathrm{~h}$ at $100{ }^{\circ} \mathrm{C}$ prior to rechromatography (ethyl acetate-pentane, 1:1), which gave a slower moving fraction $(126 \mathrm{mg}$ ) consisting predominantly $(\simeq 90 \%)$ of methyl 2,4,6-tri-O-benzoyl-3-bromo-3deoxy- $\alpha$-D-mannopyranoside (8a), sirup, ${ }^{1} \mathrm{H}$ NMR: $\delta 4.90(\mathrm{H} 1), 5.49(\mathrm{H} 2), 4.77(\mathrm{H} 3), 5.94(\mathrm{H} 4), 4.52$ (H5), 4.4-4.5 (H6), $3.48\left(\mathrm{OCH}_{3}\right) ; J_{12}=1.8 \mathrm{~Hz}$, $J_{23}=3.0, J_{34}=10.8, J_{45}=9.6 .{ }^{13} \mathrm{C}$ NMR: $\delta 97.8$ (C1), 72.7 (C2), 47.6 (C3), 69.1 (C4), 69.8 (C5), 63.0 (C6), $55.4\left(\mathrm{OCH}_{3}\right)$. The faster moving fraction could be crystallized from a small amount of ether at $-20^{\circ} \mathrm{C}$ to give $93 \mathrm{mg}$ of methyl 2,3,4-tri$O$-benzoyl-6-bromo-6-deoxy- $\alpha$-D-idopyranoside

(3a), m.p. $162-165^{\circ} \mathrm{C}$. Two recrystallizations from ethyl acetate-pentane gave m.p. $167-168{ }^{\circ} \mathrm{C}$, $[\alpha]_{\mathrm{D}}^{25}+55^{\circ}(c 1.0)$, and this product showed no m.p. depression, when mixed with the product described below. Repeated rechromatography of the mother liquors resulted in sufficient enrichment of each of the remaining two products to allow spectroscopic identification of methyl 2,4,6-tri- $O$ benzoyl-3-bromo-3-deoxy- $\alpha$-D-altropyranoside $(7 a)$, sirup, identical $\left({ }^{1} \mathrm{H}\right.$ and $\left.{ }^{13} \mathrm{CNMR}\right)$ with the product described below and of methyl 2,3,6-tri-O-benzoyl4-bromo-4-deoxy- $\alpha$-D-idopyranoside $(9 a)$, sirup, ${ }^{1} \mathrm{H}$ NMR: $\delta 4.97(\mathrm{H} 1), 5.17(\mathrm{H} 2), 5.67(\mathrm{H} 3), 4.31(\mathrm{H} 4)$, $3.62\left(\mathrm{OCH}_{3}\right) ; J_{12}=1 \mathrm{~Hz}, J_{23}=2, J_{34}=2, J_{45}=1$. ${ }^{13} \mathrm{C}$ NMR: $\delta 99.3$ (C1), 43.7 (C4), 70.8, 67.9 and
$66.5(\mathrm{C} 2, \mathrm{C} 3$ and $\mathrm{C} 5), 64.0(\mathrm{C} 6), 55.9\left(\mathrm{OCH}_{3}\right)$. Methyl 2,4,6-tri-O-benzoyl-3-bromo-3-deoxy- $\alpha$-Daltropyranoside (7a). Methyl 2-O-benzoyl-4,6-Obenzylidene-3-bromo-3-deoxy- $\alpha$ - $D$-altropyrano$\operatorname{side}^{11}(449 \mathrm{mg})$ was refluxed with $75 \%$ acetic acid for $1 \mathrm{~h}$. Evaporation to dryness, followed by preparative TLC (ethyl acetate) gave $255 \mathrm{mg}$ of methyl 2- $O$-benzoyl-3-bromo-3-deoxy- $\alpha$-D-altropyranoside as a sirup, which was benzoylated with benzoyl chloride in pyridine. Preparative TLC (methylene chloride) gave $179 \mathrm{mg}$ of $7 a$, sirup, $[\alpha]_{\mathrm{D}}^{25}-7.4^{\circ}(c 1.1)$, anal. $\mathrm{C}_{28} \mathrm{H}_{25} \mathrm{BrO}_{8}: \mathrm{C}, \mathrm{H}, \mathrm{Br}$. I H NMR: $\delta 4.89(\mathrm{H} 1), 5.57(\mathrm{H} 2), 4.79(\mathrm{H} 3), 5.55(\mathrm{H} 4)$, $4.6-4.8(\mathrm{H} 5, \mathrm{H} 6) ; J_{12}=1.0 \mathrm{~Hz}, J_{23}=J_{34}=3.5$, $\mathrm{J}_{45}=10.0 .{ }^{13} \mathrm{C} \mathrm{NMR}: \delta 99.4(\mathrm{C} 1), 72.4(\mathrm{C} 2), 45.4(\mathrm{C} 3)$,

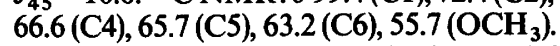

Methyl 2,3,4-tri-O-benzoyl-6-bromo-6-deoxy- $\alpha$-Daltropyranoside (3a). To a stirred suspension of methyl 4,6- $O$-benzylidene- $\alpha$-D-idopyranoside ${ }^{12}$ $(3.36 \mathrm{~g})$ and $\mathrm{BaCO}_{3}(15 \mathrm{~g})$ in tetrachloromethane $(200 \mathrm{ml})$ was added $N$-bromo-succinimide $(2.65 \mathrm{~g})$ and the solution refluxed for $2 \mathrm{~h}$, filtered while hot, evaporated to dryness, redissolved in ether and washed with water. After drying and concentration the crude sirup was benzoylated with benzoyl chloride $(5 \mathrm{ml})$ in pyridine $(50 \mathrm{ml})$ to give $3.9 \mathrm{~g}(58 \%)$ of $3 a$, m.p. $166-167{ }^{\circ} \mathrm{C}$. Recrystallization from acetone - ethanol gave m.p. $167-168{ }^{\circ} \mathrm{C},[\alpha]_{\mathrm{D}}{ }^{25}+$ $56^{\circ}$ (c 0.9), anal. $\mathrm{C}_{28} \mathrm{H}_{25} \mathrm{O}_{8} \mathrm{Br}: \mathrm{C}, \mathrm{H}, \mathrm{Br} .{ }^{1} \mathrm{H} \mathrm{NMR}$ : $\delta 5.05(\mathrm{H} 1), 5.20(\mathrm{H} 2), 5.62(\mathrm{H} 3), 5.39(\mathrm{H} 4), 4.71(\mathrm{H} 5)$, $3.6\left(\mathrm{H6}, \mathrm{H6}^{\prime}\right), 3.62\left(\mathrm{OCH}_{3}\right) ; J_{12}=1.0 \mathrm{~Hz}, J_{23}=2.5$, $J_{34}=3.0, J_{45}=1.5, J_{56}, \simeq 7 .{ }^{13} \mathrm{C}$ NMR: $\delta 99.0(\mathrm{C} 1)$, 67.0, 67.0, 67.0, 66.5 (C2, C3, C4 and C5), $30.6(\mathrm{C} 6)$, $55.8\left(\mathrm{OCH}_{3}\right)$.

Reaction of the equilibrating manno-, altro- and idobenzoxonium ions with water. The benzoxonium ions were prepared as described above and hydrolyzed with aqueous $\mathrm{NaHCO}_{3}$. After extraction with chloroform, drying and concentration, the product was deacylated with a catalytic amount of sodium methoxide in methanol overnight, neutralized with ion exchange resin (IR 120), concentrated, dissolved in water and extracted with chloroform. The water phase was concentrated and examined by ${ }^{13} \mathrm{C}$ NMR spectroscopy. The solutions obtained in this manner contained only methyl manno-, altro- and idopyranoside and the chemical shifts agred $( \pm 0.1 \mathrm{ppm})$ with previously published values. ${ }^{13}$

Acknowledgements. Micronanlyses were performed by Novo Microanalytical Laboratory. The pulsed Fourier spectrometers were provided by the Danish Natural Science Research Council. 


\section{REFERENCES}

1. Jacobsen, S. and Mols, O. Acta Chem. Scand. B 35 (1981) 163.

2. Paulsen, H. and Herold, C.-P. Chem. Ber. 103 (1970) 2450.

3. Hoffmeyer, L., Jacobsen, S., Mols, O. and Pedersen, C. Acta Chem. Scand. B 33 (1979) 175.

4. Monneret, C., Florent, J.-C., Gladieux, N. and Khuong-Huu. Q. Carbohydr. Res. 50 (1976) 35.

5. Thiem, J. and Elvers, J. Carbohydr. Res. 60 (1978) 63.

6. King, J. F. and Allbutt, A. D. Can. J. Chem. 47 (1969) 1445.

7. Evans, M. E. and Parrish, F. W. Carbohydr. Res. 54 (1977) 105.

8. Holder, N. L. and Fraser-Ried, B. Can. J. Chem. 51 (1973) 3357.

9. Buchanan, J. G. and Schwarz, J. C. J. Chem. Soc. (1962) 4770.

10. Buchanan, J. G. and Edgar, A. R. Carbohydr. Res. 49 (1976) 289 and references therein.

11. Jacobsen, S. and Pedersen, C. Acta Chem. Scand. B 28 (1974) 1024.

12. Sorkin, E. and Reichstein, T. Helv. Chim. Acta 28 (1945) 1.

13. Perlin, A. S., Casu, B. and Koch, H. J. Can. J. Chem. 48 (1970) 2596.

14. Jacobsen, S. and Pedersen, C. Acta Chem. Scand. B 28 (1974) 866.

15. Jacobsen, S., Nielsen, B. and Pedersen, C. Acta Chem. Scand. B 31 (1977) 359.

16. Jacobsen, S. and Pedersen, C. Acta Chem. Scand. B 31 (1977) 365 .

Received November 7, 1980. 